\title{
Investigating the disposal of expired and unused medication in Riyadh, Saudi Arabia: a cross-sectional study
}

\author{
Fatma Al-Shareef ${ }^{1}$ Sarah Abu El-Asrar ${ }^{2}$ - Lamyaa Al-Bakr ${ }^{2}$. Maisam Al-Amro ${ }^{2}$. \\ Fulwah Alqahtani $^{3} \cdot$ Fadilah Aleanizy $^{3} \cdot$ Sarah Al-Rashood $^{4}$
}

Received: 5 October 2015/ Accepted: 8 March 2016/Published online: 21 March 2016

(C) Springer International Publishing 2016

\begin{abstract}
Background Improper disposal of medication has several possible consequences such as childhood poisoning, environmental pollution, a negative impact on wildlife, and antibiotic resistance. The number of studies conducted to characterize pharmaceutical disposal practices is limited, particularly in the Middle East. Objective The aim of this cross-sectional study was to examine the behaviour of individuals with respect to the disposal of expired and unused medications. Furthermore, we aimed to identify the best methods of education regarding appropriate, safe disposal of medication. Setting The study was carried out in King Khalid University Hospital (KKUH), and King Saud University (KSU), during a 3-month period from February 2015 to April 2015. Method Twelve hundred patients were randomly selected from KKUH and KSU. Participants were invited to complete paper-based questionnaire with self enumeration. Pilot testing was conducted and involved 50 randomly selected participants. Main outcome measures The proportion of expired
\end{abstract}

Electronic supplementary material The online version of this article (doi:10.1007/s11096-016-0287-4) contains supplementary material, which is available to authorized users.

Fatma Al-Shareef

shareeff@ngha.med.sa

1 Saudi Medication Safety Centre, Ministry of National Guard, Health Affairs, Riyadh 22490, Saudi Arabia

2 College of Pharmacy, King Saud University, Riyadh 22452, Saudi Arabia

3 Department of Pharmaceutics, College of Pharmacy, King Saud University, Riyadh 22452, Saudi Arabia

4 Department of Medicinal Chemistry, College of Pharmacy, King Saud University, Riyadh 22452, Saudi Arabia medications present in the home and their therapeutic groups, disposal methods of expired and unused medications, and preferred educational methods regarding safe and proper disposing of medications. Results A substantial proportion $(79.15 \%)$ of respondents disposed of unwanted medication via household waste, while a small proportion $(1.70 \%)$ returned unwanted medication to a pharmacy. Although currently practised disposal methods are undoubtedly unsuitable, $70.20 \%$ of respondents considered finding appropriate, safe methods via which to dispose of unwanted medication their responsibility, and $78.6 \%$ expressed an interest in receiving information concerning the correct disposal of unwanted medication. Conclusion We have demonstrated that a low percentage of respondents have ever received information regarding correct medication disposal. Moreover, the results have shown that over half of the respondents store antibiotics in their households. Additionally, respondents weren't aware of the consequences of keeping expired medication at home. It is quite clear that the awareness of proper and safe drug disposal among the Saudi population is quite low making it a priority of concerned authorities to implement educational programs.

Keywords Medication disposal - Medication waste . Saudi Arabia $\cdot$ Unused medications

\section{Impacts on practice}

- Storage of unused and expired medications at home may lead to unnecessary self medication and poisonings, thus, establishment of medication take-back program in Saudi Arabia is required. 
- The presence of leftover antibiotics among stored medications at home indicates antibiotic abuse and may contribute to antibiotic resistance, which necessitates the implementation of decisive policy action to reduce the use of antibiotics without a prescription.

- Awareness of the preferable educational methods by population about proper disposal of unused medication is very important in order to deliver information in effective, enjoyable and stimulating methods.

\section{Introduction}

The number of medications currently used worldwide is high. In 2013, 1453 medications had received United States Food and Drug Administration (USFDA) approval [1]. Several countries have developed policies for the disposal of unused and expired medications. In the United States, the Food and Drug Administration (FDA) and Office of National Drug Control Policy developed federal guidelines to govern the disposal of drugs [2]. In the United Kingdom, selected pharmacies are required to accept unwanted medication from patients on behalf of the National Health Service (NHS) or waste contractors [3]. Moreover, the Pharmaceutical Services Negotiating Committee (PSNC) has worked with the Department of Health, Environment Agency, and others to prepare guidelines for pharmacies concerning the correct disposal of medication [3]. In Australia, the government established the National Return and Disposal of Unwanted Medicines (NatRUM) program since 1998 to facilitate the safe disposal of medications in the community [4]. This program is available for every pharmacy in Australia by which unwanted medications can be returned and disposed of safely free of charge [5]. In Mexico, manufacturers, distributors, and hospitals were responsible for the disposal of expired medication under general law governing the handling and processing of waste. In addition, some states in Mexico have implemented programs for the collection of unwanted medications from households [6]. In the Republic of Serbia, pharmacies are obliged by law to accept unused and expired medications from the public and retain them as pharmaceutical waste, which is returned to wholesalers, manufacturers, or special operators trained in the collection and transport of waste for destruction [7].

Environmental pollution is one of the main issues that cause concern regarding the improper disposal of medications. Medications enter the environment in several ways, one of which is via the disposal of unwanted medication. In the past decade, more than 100 different medications, including fluoxetine, gemfibrozil, and ibuprofen, have been discovered in the environment, detected in wastewater [8].
Moreover, there is increasing concern that antibiotics found in the environment may contribute to antibiotic resistance [9]. Unfortunately, there is also evidence that pharmaceuticals found in the environment could exert a negative impact on wildlife. For instance, diclofenac found in wastewater has been shown to affect renal function in brown trout (Salmo trutta) [10]. Furthermore, the disposal of medication via household waste increases the risk of exposure for pets and humans, particularly young children. Children and pets are able to access household waste easily. The majority of children who are poisoned by medication gain access to the medication at home [11]. For example, the Food and Drug Administration (FDA) has reported numerous deaths due to accidental exposure to discarded fentanyl patches [12].

Therefore many studies have examined and tracked methods and patterns of medication disposal and the associated risks. Such studies have been conducted in Siberia (Russia), New Zealand, the USA, the UK, and other countries [7, 13-17].

Special attention must be directed towards Saudi Arabia. The cost of medication wastage in Saudi Arabian homes has been estimated at 10 USD (United States Dollars) per person per household, with annual national medication wastage costs of 150 million USD [18]. Many factors may contribute to the considerable burden of pharmaceutical waste from the perspectives of both quantity and quality. In 2010, the total pharmaceutical expenditure (TPE) in Saudi Arabia was 13.5 billion SAR (3.5 billion USD) [19]. To our knowledge, Saudi Arabia does not have comprehensive drug disposal policies. It has a total population of $28,829,000$ and a high prevalence rate for chronic disease. The World Health Organization (WHO) reported that $69 \%$ of all deaths in Saudi Arabia occur as a result of chronic disease [20]. In addition, governmental healthcare facilities provide all Saudi citizens with free medication.

The number of studies conducted to examine medication disposal practices in the Middle East is limited, particularly in Saudi Arabia. Only one recent study has assessed the safety measures used by parents to store and dispose of medication to prevent their children from being poisoned [21]. Several studies were conducted in Kuwait to explore practice, awareness, and opinion concerning the disposal of unused and expired medications [22, 23]. Public awareness surrounding the disposal of medication is considered low in Saudi Arabia.

\section{Aim of the study}

The aim of this study was to investigate the behaviour of individuals in Riyadh in the disposal of expired and unused medication. Furthermore, we aimed to identify the best 
methods to educate the public regarding appropriate, safe disposal of medication.

\section{Ethics approval}

This study received approval from the institutional review board of King Khalid University Hospital (KKUH) (project number: E-15-1474).

\section{Methodology}

A cross-sectional, survey-based study was conducted over a period of 3 months from February to April 2015. Pilot testing, involving 50 randomly selected participants, was performed to assess the clarity and validity of the questionnaire. This resulted in the omission, addition, or modification of questions to ensure participant understanding.

The survey (Appendix-A in supplementary material) was distributed upon completion of pilot testing. The required sample size was calculated as 1200 , with random participant selection. There was no specific method to recruit participants. Individuals in the mentioned areas were approached randomly without any previous measures. $50 \%(n=600)$ of the participants were recruited from King Khalid University Hospital (KKUH). KKUH is an 800-bed facility that provides primary and secondary care services to patients from the Northern Riyadh area and referral-based tertiary care services to all Saudi citizens. The survey was distributed in pharmacy and primary care clinic waiting areas. The main target was patients, however; personnel working in the area were also included. In addition, $50 \%(n=600)$ of the participants were recruited from King Saud University and included both students and staff members. This allowed for a diverse sample.

Potential participants were informed about the purpose of the study and assured that any data collected would remain confidential. If participants chose not to participate in the study, their reasons for refusal were noted. Participants who provided verbal consent to participate in the study completed the paper-based survey via self-enumeration. It took an average of $10 \mathrm{~min}$ to complete the questionnaire. The questionnaire was completed and returned back immediately.

The original English questionnaire was translated into Arabic, and participants received their preferred version. The questionnaire contained 16 items divided into three sections: Section 1: demographic information; Section 2: quantification and characterization of unused and expired medication in the home; and Section 3: practice and attitude regarding the disposal of unused or expired medication.
Statistical analysis was performed using Statistical Package for the Social Sciences (SPSS) version 21 (SPSS Inc., Chicago, IL, USA). Chi square and Fisher's exact tests were performed to compare nominal variables with demographic characteristics. Statistical significance was set at $p<0.05$.

\section{Results}

Thousand-fifty-seven questionnaires $(88.1 \%)$ were completed by respondents and included in the analysis.

\section{Demographic information}

The proportion of women $(58.9 \%)$ in the sample was slightly higher relative to that of men $(41 \%)$. The most common age group was 18-25 years (44.8\%), and more than half of the respondents $(65.1 \%)$ held a bachelor's degree. Respondents' demographic characteristics are shown in Table 1.

\section{Influence of demographic characteristics on drug disposal awareness and practice}

Respondents' overall awareness regarding drug disposal was very low regardless of their demographic characteristics. $55.3 \%$ of respondents were unaware of the consequences of keeping expired medication in the home (Table 2). In addition, when the respondent were asked if they think that prescription medications should be disposed of differently than non-prescription medications, 44.7 and

Table 1 Respondents' demographic characteristics $(n=1057)$

\begin{tabular}{lc}
\hline Parameter & $\%(\mathrm{n})$ \\
\hline Gender & \\
Female & $58.94(623)$ \\
Male & $41.05(434)$ \\
Age & \\
$18-25$ & $44.84(474)$ \\
$26-35$ & $25.45(269)$ \\
$36-45$ & $18.45(195)$ \\
$46-55$ & $7.66(81)$ \\
$>55$ years & $3.60(38)$ \\
Educational level & \\
None & $1.61(17)$ \\
Primary school & $1.80(19)$ \\
Elementary school & $3.41(36)$ \\
High school & $19.50(206)$ \\
Bachelor's degree & $65.18(689)$ \\
Higher & $8.51(90)$ \\
\hline
\end{tabular}


Table 2 Influence of demographic characteristics on drug disposal awareness and practice

\begin{tabular}{|c|c|c|c|c|}
\hline Response & Frequency & Gender & Age & Educational level \\
\hline \multicolumn{5}{|c|}{ Differentiation between disposal of prescription and non-prescription medications } \\
\hline Yes & $16.08(170)$ & \multirow[t]{3}{*}{ No difference $(p=0.139)^{*}$} & \multirow{3}{*}{$\begin{array}{l}\text { No difference } \\
\quad(p=0.092)^{*}\end{array}$} & \multirow[t]{3}{*}{ No difference $(p=0.156)^{*}$} \\
\hline No & $44.75(473)$ & & & \\
\hline I don’t know & $39.17(414)$ & & & \\
\hline \multicolumn{5}{|c|}{ Willingness to use drug collection facilities } \\
\hline Very willing & $47.02(497)$ & \multirow[t]{4}{*}{ Female $>$ male $(p<0.001)^{*}$} & \multirow{4}{*}{$\begin{array}{l}\text { Willingness increased } \\
\quad \text { with age }(p=0.002)^{*}\end{array}$} & \multirow[t]{4}{*}{ No difference $(p=0.917)^{*}$} \\
\hline Somewhat willing & $34.53(365)$ & & & \\
\hline Neither willing nor unwilling & $13.72(145)$ & & & \\
\hline Very unwilling & $4.73(50)$ & & & \\
\hline \multicolumn{5}{|c|}{ Awareness of consequences of storing expired medication in the home } \\
\hline No consequences & $11.64(123)$ & \multirow[t]{3}{*}{ No difference $(p=0.475)^{*}$} & \multirow{3}{*}{$\begin{array}{l}\text { Awareness increased } \\
\text { with age }(p<0.001)^{*}\end{array}$} & \multirow{3}{*}{$\begin{array}{l}\text { Awareness highest in those } \\
\text { with higher education } \\
(p<0.001)^{*}\end{array}$} \\
\hline I don't know & $55.35(585)$ & & & \\
\hline Yes & $33.02(349)$ & & & \\
\hline \multicolumn{5}{|c|}{ Individual responsibility for finding an appropriate means of disposing of medication } \\
\hline Yes & $70.20(742)$ & \multirow[t]{2}{*}{ Female $>$ male $(p<0.001)^{*}$} & \multirow{2}{*}{$\begin{array}{l}\text { Feeling of responsibility } \\
\text { increased with age } \\
(p=0.002)^{*}\end{array}$} & \multirow{2}{*}{$\begin{array}{l}\text { Feeling of responsibility } \\
\text { highest in those with higher } \\
\text { education }(p=0.005)^{*}\end{array}$} \\
\hline No & $29.80(315)$ & & & \\
\hline
\end{tabular}

* Appendix B in supplementary material

$39.1 \%$ of them answered with "no" and "I don't know", respectively (Table 2). Associations between respondents' demographic characteristics (gender, age, and educational level) and several items used to assess drug disposal awareness and practice were examined. There were no significant associations between any demographic characteristics and differentiation between the disposal of prescription and non-prescription medications (Table 2). As shown in Table 2, willingness to use drug collection facilities and awareness of the consequences of storing expired medication in the home increased with age $(p<0.05)$, also individual responsibility for finding an appropriate means of disposing of medication increased with increasing age. Interestingly, women felt greater responsibility for finding an appropriate means of disposing of medication and willingness to return medication to collection facilities relative to that of men (Table 2). Alarmingly, educational level did not exert a positive influence on the parameters measured, with the exception of awareness of the consequences of storing expired medication in the home and feeling of responsibility for finding an appropriate means of disposing of medication (Table 2).

\section{Quantification and characterization of expired and unwanted medication in the home}

In total, $75.80 \%$ of respondents used medication, including both prescription and non-prescription medication, and $86,9.6$, and $4.4 \%$ had $1-5,6-10$, and $>10$ different types of medication at home, respectively. Furthermore, $21.4 \%$ of respondents reported having expired medication at home. Of these respondents, 82.4, 13.1, and 4.5\% had 1-5, $6-10$, and $>10$ different types of expired medication at home, respectively.

Figure 1 shows the therapeutic medication groups present in the home including expired, unused and used medications. Some respondents selected more than one therapeutic group. The most common therapeutic medication group kept in the home was cold, cough, and flu medication, followed by vitamins/nutritional supplements and antibiotics. Importantly, $51.9 \%$ (549 from 1057) of respondents reported having antibiotics at home.

\section{Attitudes and methods of medication disposal}

As shown in Fig. 2, disposing of medication via household waste was the most common method of disposal for unused and expired medications $(79.1 \%)$, followed by flushing them down the toilet or sink $(7 \%)$; however, the rate at which the latter was used was relatively low relative to that of the former (Fig. 2). Other questions asked revealed that $61.7 \%$ of respondents believed that disposing of medication by flushing it down the toilet was inappropriate. In addition, $70.2 \%$ of respondents believed that finding alternative means of disposing of medication was their responsibility, and $81.5 \%$ were very willing or somewhat willing to use drug collection facilities if available (Table 2). 
Fig. 1 Therapeutic groups of all medications present in the home $(n=1057)$

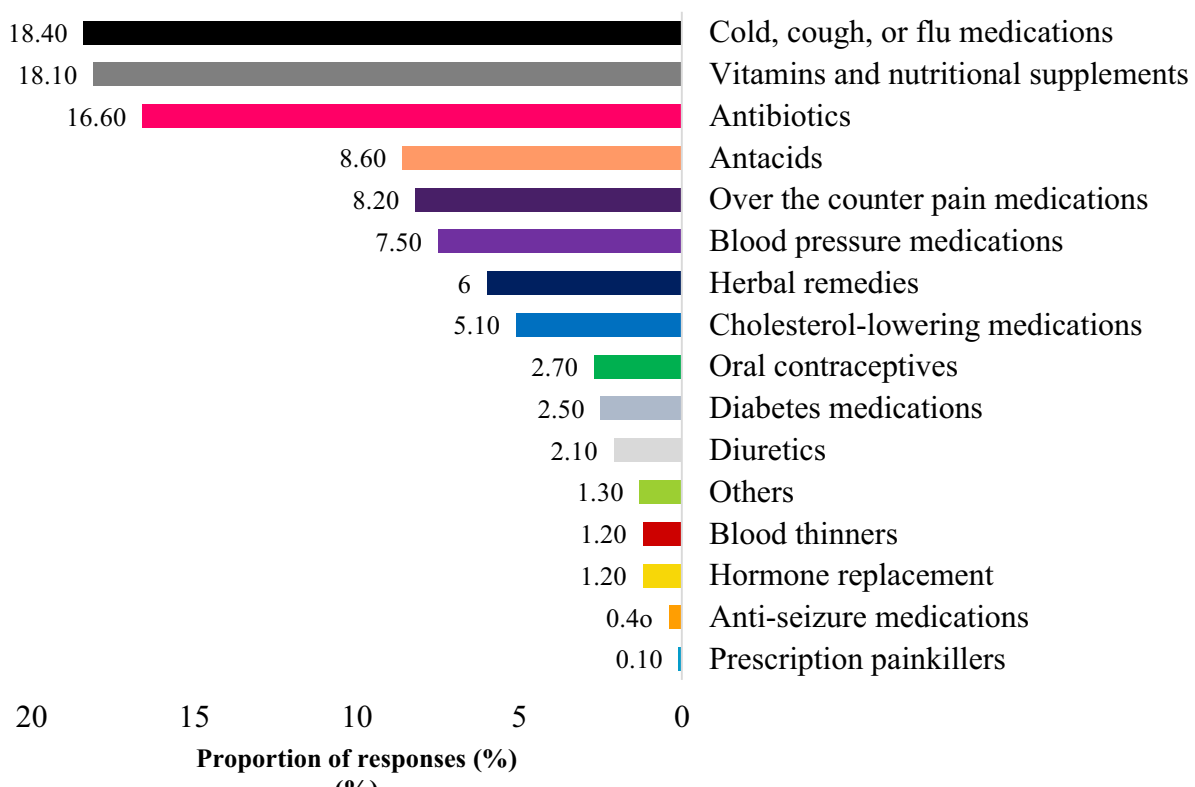

(\%)
Fig. 2 Responses concerning the disposal of unused and expired medication $(n=1057)$

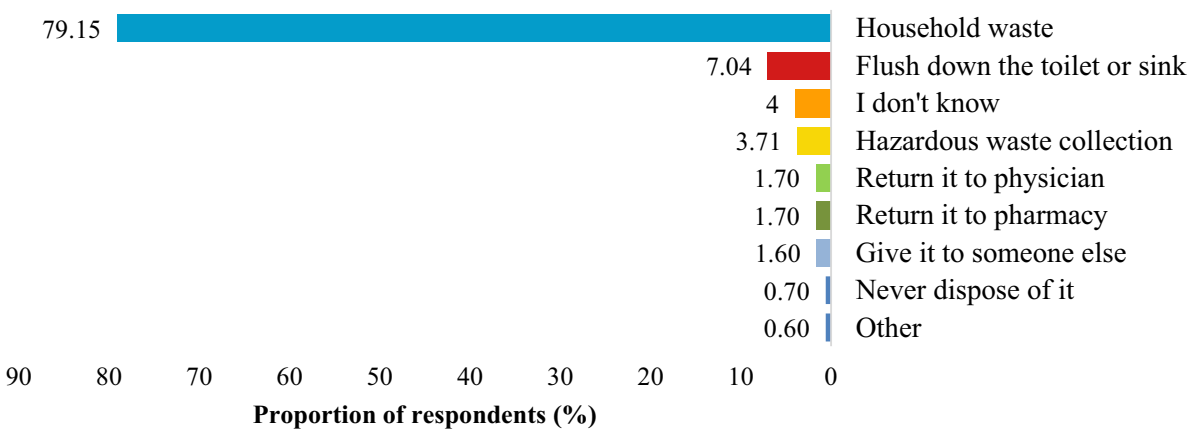

\section{Preferred methods of education regarding the disposal of unused or expired medication}

Only $9.1 \%$ of respondents had received instructions concerning the correct disposal of medication. When respondents were asked whether they wished to receive information regarding the correct disposal of medication, $78.6 \%$ answered "yes." The preferred educational methods are shown in Fig. 3.

\section{Discussion}

Improper disposal of unwanted or surplus medicines is one of the main routes via which household medications enter the environment [24], which exerts an impact on people and the natural environment. Therefore, the current study examined medication disposal practices used by members of the public in Riyadh.

The results of this study showed a high rate of disposal of medication via household waste $(79.1 \%)$. Although a study conducted by Ruwailia et al. [21] focused on medication storage, their result regarding medication disposal was comparable to our finding where $87 \%$ of participants in their study disposed of their unused medication via household waste. Moreover, this method has been identified as the most common means of disposal in several other countries including the USA, the UK, Serbia, and Kuwait [7, 13-17, 23].

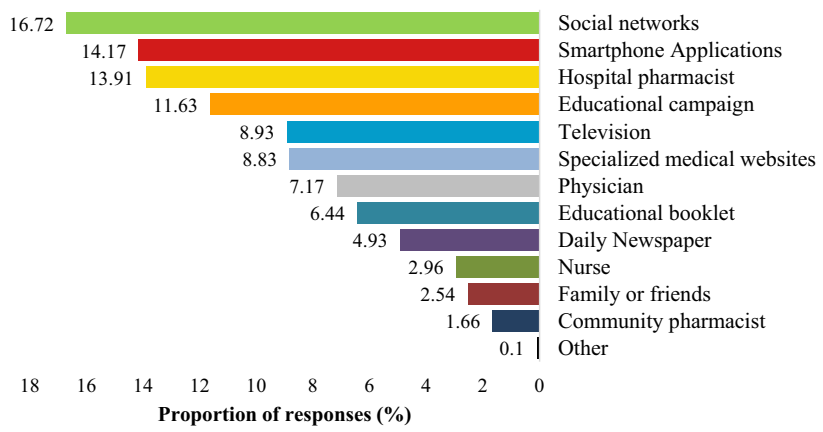

Fig. 3 Preferred educational methods $(n=831)$ 
The second most commonly reported disposal method in the current study was flushing medication down the toilet or sink; however, this rate was low $(7 \%)$ relative to that of disposal via household waste. The results of a corporate survey conducted in the UK revealed that $63 \%$ of respondents discarded unused medications via household waste, $11 \%$ disposed of them via the sink or toilet, and $22 \%$ returned them to a pharmacy [16]. A study conducted in the USA showed that $54 \%$ of respondents disposed of unwanted medications via household waste, while $35 \%$ emptied them down the toilet or sink and $1.4 \%$ returned them to a pharmacy [24]. Research recently conducted in the USA reported that $62.7 \%$ of participants disposed of unused medications via household waste, $18 \%$ flushed them down the toilet, and $11 \%$ returned them to a pharmacy [15]. In Serbia, 85 and $8.7 \%$ of respondents disposed of medication via household waste and the toilet, respectively [7]. Similarly, a study conducted in Kuwait indicated that $73 \%$ of the pharmacists surveyed discarded unused medications in household waste, 32 and $9 \%$ disposed of them via the sink and toilet, respectively, and $10 \%$ returned them to the Central Drug Store [23]. Therefore, the medication disposal patterns revealed in our study are congruent with findings reported in previous studies.

The present study showed that only $2 \%$ of respondents returned unwanted medication to a pharmacy. This low proportion could be explained by the lack of comprehensive drug disposal policies and pharmacies with take-back programs in Saudi Arabia [21]. In comparison, returning unwanted medication to a pharmacy was the most prominent disposal method in Sweden, where $45 \%$ of respondents did so [24]. Moreover, none of the Swedish respondents reported using the toilet as a means of disposal [24]. This finding could be the result of Apoteket AB, a Swedish system via which unwanted medications are returned to a pharmacy and appropriate handling of returned medication is guaranteed [25].

The current study also found that $51.9 \%$ of respondents stored leftover antibiotics at home. This result may indicate potential antibiotic abuse, particularly as community pharmacies in Saudi Arabia dispense antibiotics without requesting a prescription, as shown in previous reports [26, 27]. This necessitates the implementation of decisive policy action to reduce the use of antibiotics without a prescription and reinforcement of public campaigns to promote improved use of antibiotics.

One of our aims was to identify the most appropriate methods of education regarding the disposal of expired and unused medication. It comes as no surprise that only $9.1 \%$ of respondents had received instructions regarding the correct disposal of medication. This is related to the lack of established drug disposal policy in Riyadh.

When asked whether they wished to receive information regarding the correct disposal of medication, $78.6 \%$ of respondents answered "yes." In addition, $70.2 \%$ of respondents believed that finding alternative means of disposing of medication was their responsibility, which reflects enthusiasm to learn. Cooperation between several governmental sectors in implementing nationwide educational campaigns would ensure that most citizens receive appropriate information. This study revealed that respondents' most preferred methods of learning about medication disposal were social networks, smartphone applications, and hospital pharmacists. This was expected, as in one study, the Saudi Arabian population spent the most time online per day $(5.1 \mathrm{~h})$ and had a higher proportion of people $(91 \%)$ who used social media relative to those of other countries [28].

The study was subject to some limitations. There was a lack of manpower, and the data were collected through self administration by respondents which might have introduced some bias. Additionally, the study was restricted to the KKUH and KSU; therefore, the results may not reflect disposal practices in other regions of the capital. However, this provides an opportunity for future studies to examine disposal practices in Riyadh, and more extensively, nationwide. Moreover, respondents retrieve some information from memory which depends on respondent's cognitive ability and memory capacity.

\section{Conclusion}

The awareness of individuals regarding safe drug disposal in Saudi Arabia is quite low. The most common method of medication disposal is through the household trash, regardless of medication type. Such a practice poses possible risks for the population and needs to be addressed. However, individuals are quite eager to be educated about the safe and proper disposal of unwanted medication. Gender, age, and educational level have an impact on practice and attitude which should be taken into account should corrective measures be implemented.

Acknowledgments We would like to thank Amir S. Marzouk from $\mathrm{KKUH}$, College of medicine research centre for his help in statistical analysis.

Funding The authors acknowledge the Research Centre of the Science and Medical studies Departments at King Saud University for financial support.

Conflicts of interest The authors report no conflicts of interest. 


\section{References}

1. Kinch MS, Haynesworth A, Kinch SL, Hoyer D. An overview of FDA-approved new molecular entities: 1827-2013. Drug Discov Today. 2014;19(8):1033-9.

2. USFDA. How to dispose of unused medicines. 2013 [updated 2013 Dec 4; cited 2015 Apr 1]. http://www.fda.gov/For Consumers/ConsumerUpdates/ucm101653.htm.

3. PSNCP. Disposal of unwanted medicines. 2015 [updated 2015 Jan 1; cited 2015 Aug 1]. http://psnc.org.uk/services-commis sioning/essential-services/disposal-of-unwanted-medicines/.

4. Limited TNRaDoUM. Return unwanted medicines (The RUM Project) Australia. 2011 [updated 2011 Feb 1; cited 2015 Aug 1]. www.returnmed.com.au.

5. Bergen PJ, Hussainy SY, George J, Kong DC, Kirkpatrick CM. Safe disposal of prescribed medicines. Aust Prescr. 2015;38(3):90-2.

6. Gracia-Vasquez SL, Ramirez-Lara E, Camacho-Mora IA, CantuCardenas LG, Gracia-Vasquez YA, Esquivel-Ferrino PC, et al. An analysis of unused and expired medications in Mexican households. Int J Clin Pharm. 2014;37(1):121-6.

7. Kusturica MP, Sabo A, Tomic Z, Horvat O, Solak Z. Storage and disposal of unused medications: knowledge, behavior, and attitudes among Serbian people. Int J Clin Pharm. 2012;34(4): 604-10.

8. Monteiro SC, Boxall AB. Occurrence and fate of human pharmaceuticals in the environment. Rev Environ Contam Toxicol. 2010;202:53-154.

9. Kummerer K. Resistance in the environment. J Antimicrob Chemother. 2004;54(2):311-20.

10. Hoeger B, Kollner B, Dietrich DR, Hitzfeld B. Water-borne diclofenac affects kidney and gill integrity and selected immune parameters in brown trout (Salmo trutta f. fario). Aquat Toxicol. 2005;75(1):53-64.

11. Ozanne-Smith J, Day L, Parsons B, Tibballs J, Dobbin M. Childhood poisoning: access and prevention. J Paediatr Child Health. 2001;37(3):262-5.

12. Paparella SF. A serious threat to patient safety: the unintended misuse of FentaNYL patches. J Emerg Nurs. 2013;39(3):245-7.

13. Vellinga A, Cormican S, Driscoll J, Furey M, O’Sullivan M, Cormican M. Public practice regarding disposal of unused medicines in Ireland. Sci Total Environ. 2014;15(478):98-102.

14. Tong AY, Peake BM, Braund R. Disposal practices for unused medications in New Zealand community pharmacies. J Prim Health Care. 2011;3(3):197-203.
15. Law AV, Sakharkar P, Zargarzadeh A, Tai BW, Hess K, Hata M, et al. Taking stock of medication wastage: unused medications in US households. Res Social Adm Pharm. 2015;11(4):571-8.

16. Bound JP, Voulvoulis N. Household disposal of pharmaceuticals as a pathway for aquatic contamination in the United kingdom. Environ Health Perspect. 2005;113(12):1705-11.

17. Glassmeyer ST, Hinchey EK, Boehme SE, Daughton CG, Ruhoy IS, Conerly O, et al. Disposal practices for unwanted residential medications in the United States. Environ Int. 2009;35(3):566-72.

18. Abou-Auda HS. An economic assessment of the extent of medication use and wastage among families in Saudi Arabia and Arabian Gulf countries. Clin Ther. 2003;25(4):1276-92.

19. SFDA. Saudi Arabia pharmaceutical country profile. WHO; 2012 [updated 2012 Apr 18; cited 2015 Apr 1]. http://www.who.int/ medicines/areas/coordination/Saudi_ArabiaPSCP_Narrative201204-18_Final.pdf.

20. WHO. Chronic diseases are the major cause of death and disability worldwide. 2015 [updated 2015 Jan 1; cited 2015 Apr 1]. http://www.who.int/chp/chronic_disease_report/saudi_arabia.pdf.

21. Ruwailia NA, Balushia AA, Alharfb A, AlShaharanib H, Eldalic A. Do parents in Saudi Arabia store medications safely? Int J Pediatr Adolesc Med. 2014;1(1):21-5.

22. Abahussain EA, Ball DE, Matowe WC. Practice and opinion towards disposal of unused medication in Kuwait. Med Princ Pract. 2006;15(5):352-7.

23. Abahussain E, Waheedi M, Koshy S. Practice, awareness and opinion of pharmacists toward disposal of unwanted medications in Kuwait. Saudi Pharm J. 2012;20(3):195-201.

24. Tong AY, Peake BM, Braund R. Disposal practices for unused medications around the world. Environ Int. 2011;37(1):292-8.

25. Persson M, Sabelstrom E, Gunnarsson B. Handling of unused prescription drugs-knowledge, behaviour and attitude among Swedish people. Environ Int. 2009;35(5):771-4.

26. Belkina T, Al Warafi A, Eltom EH, Tadjieva N, Kubena A, Vlcek J. Antibiotic use and knowledge in the community of Yemen, Saudi Arabia, and Uzbekistan. J Infect Dev Ctries. 2014;8(4): 424-9.

27. Bawazir SA. Prescribing pattern at community pharmacies in Saudi Arabia. Int Pharm J. 1992;6(5):222-4.

28. Langmia K, Tyree T, O’Brien P, Sturgis I. Social media: pedagogy and practice. Lanham: University Press of America; 2013. 